\title{
A six-year descriptive analysis of hospitalisations for ambulatory care sensitive conditions among people born in refugee-source countries

\author{
Ignacio Correa-Velez*1, Zahid Ansari², Vijaya Sundararajan ${ }^{3}$, Kaye Brown ${ }^{4}$ \\ and Sandra M Gifford ${ }^{1}$
}

\begin{abstract}
Address: ${ }^{1}$ Refugee Health Research Centre, La Trobe University, Victoria 3086, Australia, ${ }^{2}$ Chronic Disease Surveillance and Epidemiology Section, Public Health Branch, Department of Human Services, 15/50 Lonsdale Street, Melbourne, Victoria 3000, Australia, ${ }^{3}$ Programs Branch, Health Surveillance and Evaluation Section, Department of Human Services, 19/50 Lonsdale Street, Melbourne, Victoria 3000, Australia and ${ }^{4}$ Statewide Elective Surgery Program, Access and Metropolitan Performance Branch, Department of Human Services, 18/50 Lonsdale Street, Melbourne, Victoria 3000, Australia
\end{abstract}

Email: Ignacio Correa-Velez* - i.correa-velez@latrobe.edu.au; Zahid Ansari - Zahid.Ansari@dhs.vic.gov.au;

Vijaya Sundararajan -Vijaya.Sundararajan@dhs.vic.gov.au; Kaye Brown - Kaye.Brown@dhs.vic.gov.au;

Sandra M Gifford - s.gifford@latrobe.edu.au

* Corresponding author

Published: 3 October 2007

Population Health Metrics 2007, 5:9 doi:10.1 186/1478-7954-5-9

This article is available from: http://www.pophealthmetrics.com/content/5/I/9

(c) 2007 Correa-Velez et al; licensee BioMed Central Ltd.

This is an Open Access article distributed under the terms of the Creative Commons Attribution License (http://creativecommons.org/licenses/by/2.0), which permits unrestricted use, distribution, and reproduction in any medium, provided the original work is properly cited.

\begin{abstract}
Background: Hospitalisation for ambulatory care sensitive conditions (ACSHs) has become a recognised tool to measure access to primary care. Timely and effective outpatient care is highly relevant to refugee populations given the past exposure to torture and trauma, and poor access to adequate health care in their countries of origin and during flight. Little is known about ACSHs among resettled refugee populations. With the aim of examining the hypothesis that people from refugee backgrounds have higher ACSHs than people born in the country of hospitalisation, this study analysed a six-year state-wide hospital discharge dataset to estimate ACSH rates for residents born in refugee-source countries and compared them with the Australia-born population.
\end{abstract}

Methods: Hospital discharge data between I July 1998 and 30 June 2004 from the Victorian Admitted Episodes Dataset were used to assess ACSH rates among residents born in eight refugee-source countries, and compare them with the Australia-born average. Rate ratios and $95 \%$ confidence levels were used to illustrate these comparisons. Four categories of ambulatory care sensitive conditions were measured: total, acute, chronic and vaccine-preventable. Country of birth was used as a proxy indicator of refugee status.

Results: When compared with the Australia-born population, hospitalisations for total and acute ambulatory care sensitive conditions were lower among refugee-born persons over the six-year period. Chronic and vaccinepreventable ACSHs were largely similar between the two population groups.

Conclusion: Contrary to our hypothesis, preventable hospitalisation rates among people born in refugee-source countries were no higher than Australia-born population averages. More research is needed to elucidate whether low rates of preventable hospitalisation indicate better health status, appropriate health habits, timely and effective care-seeking behaviour and outpatient care, or overall low levels of health care-seeking due to other more pressing needs during the initial period of resettlement. It is important to unpack dimensions of health status and health care access in refugee populations through ad-hoc surveys as the refugee population is not a homogenous group despite sharing a common experience of forced displacement and violence-related trauma. 


\section{Background}

Hospitalisation for ambulatory care sensitive conditions (ACSHs) has become a recognised tool to measure access to primary care [1-3]. Ambulatory Care Sensitive Conditions (ACSCs) have been defined as those conditions for which "the provision of timely and effective outpatient care can help to reduce the risks of hospitalization by either preventing the onset of an illness or condition, controlling an acute episodic illness or condition, or managing a chronic disease or condition" [4](p.163). Some examples of ACSCs are influenza, pneumonia, asthma, hypertension, congestive heart failure, diabetes complications, and nutritional deficiencies.

The rate of ACSHs has been found to be influenced by a number of factors such as income $[1,5]$, health insurance status [6], access to regular primary care [7], continuity of care [8], and race and ethnicity [3]. Minority race/ethnic groups have been observed to be at greater risk of being hospitalised for a preventable condition [3,9-11] and their higher hospitalisation rates persist after adjusting for disease prevalence [9].

Given the challenges of the growing problem of forced displacement, and in view of the internationalisation of refugee resettlement [12], it is important for governments, public health professionals, and health service providers in resettlement countries to obtain evidence on humanitarian arrivals' access to primary care and preventable hospitalisation. Timely and effective outpatient care is highly relevant to refugee populations given the past exposure to torture and trauma, and poor access to adequate health care in their countries of origin and during flight $[13,14]$. ACSHs among refugee populations remain largely undocumented. With the aim of examining the hypothesis that people from refugee backgrounds have higher ACSHs than people born in the country of hospitalisation, this study analysed a six-year state-wide hospital discharge dataset to estimate ACSH rates for residents born in refugee-source countries and compared them with the Australia-born population. Australia has a publicly-funded universal health care scheme for all citizens and permanent residents, including humanitarian entrants, which provides access to free treatment in public hospitals, and free or subsidised treatment by general practitioners, specialists and optometrists.

\section{Methods}

\section{Data overview}

We used hospital discharge data between 1 July 1998 and 30 June 2004 from the Victorian Admitted Episodes Dataset (VAED). The VAED contains data on all admitted patients from public and private acute hospitals in the state of Victoria. It also includes admitted patient activity submitted by acute facilities in rehabilitation and extended care institutions and day procedure centres [15]. Although VAED is an administrative dataset that is collected for operational reasons, it provides useful information about acute health care use and health-related outcomes. Clinical data are stored as ICD-10-AM [16] codes in 25 (from 1998/99 to 2002/03) to 40 (2003/04) diagnosis and procedures fields. We obtained permission to use de-identified data from the Victorian Department of Human Services.

\section{Study population}

In this study, country of birth was used as a proxy indicator of refugee status. The VAED lacks data on immigration status and on ethnicity beyond country of birth (with the exemption of Indigenous Australians). Refugee-source countries are defined as those countries where large numbers of people have been forcibly displaced due to persecution, armed conflict and war [13]. In this study, we have included eight countries for which the majority of entrants to Victoria have arrived under the immigration humanitarian program $[17,18]$. These countries are: Afghanistan, Bosnia-Herzegovina, Burma, Eritrea, Ethiopia, Iraq, Somalia and Sudan.

\section{Definition of Ambulatory Care Sensitive Conditions (ACSCs)}

We used the classification of ACSC applied in the Victorian Ambulatory Care Sensitive Conditions Study [19], which draws from previous research $[6,20]$. According to this classification, there are three categories of ACSCs:

(a) Acute ACSCs (reducing morbidity and pain through timely and appropriate treatment): This category includes acute disease for which hospitalisation is avoidable, for example, dehydration/gastroenteritis, kidney infection, perforated ulcer, cellulitis, pelvic inflammatory disease, ear, nose and throat infections, and dental conditions. In this category, the conditions may not be preventable but theoretically do not result in hospitalisation if adequate and timely primary care is received.

(b) Chronic ACSCs (reducing the effect of chronic disease and prolonging life): This category includes selected chronic diseases for which hospitalisation is avoidable, for example, diabetes, asthma, angina, hypertension, congestive heart failure, chronic obstructive pulmonary disease. In this category, the conditions may be preventable through behaviour modification and lifestyle change, but they can also be managed effectively through primary care to prevent deterioration and hospitalisation.

(c) Vaccine-preventable ACSCs (reducing the incidence of preventable diseases): This includes hospitalisation for influenza, bacterial pneumonia, tetanus, measles, mumps, rubella, pertussis and polio-conditions for which 
vaccination is available. In this category, the actual conditions are deemed to be preventable, rather than the hospitalisation. There is, however, a misclassification bias with respect to vaccine-preventable ACSC in the context of this study. Admissions due to vaccine-preventable ACSC cannot be assessed among children born in Australia to refugee families because they are classified as Australia-born.

The ACSCs identified using the ICD-10-AM codes in the diagnosis fields of the VAED are shown in Table 1.

\section{ACSC admission rates and rate ratios}

ACSC admission rates were age-standardised using the direct method [21]. Annual Victorian population estimates for most of the refugee-source countries included in this analysis were not readily available. Therefore, population figures for individual refugee-source countries were estimated by adding the number of arrivals in Victoria born in that country [17] to the number of individuals recorded at the previous census [22]. The Australia-born population was estimated using figures from the 1996 and 2001 censuses [22]. The estimated resident population of Victoria was used as the standard population.
A random sample of 100,000 Australia-born admissions was taken for each year. Rate ratios are used throughout the paper to compare the ACSC between Australia-born and refugee-source country-born [21]. A rate ratio greater than 1.0 indicates that ACSC admissions were higher for refugee-source-country-born than for Australia-born persons. Confidence levels of $95 \%$ are used to assess and report the precision of ACSC admission rates and rate ratios. We used the method based on the gamma distribution [23] to calculate confidence intervals for age-adjusted rates.

\section{Results}

The number and standardised ratios of total, acute, chronic, and vaccine-preventable ACSHs for persons born in refugee-source countries over the six-year period (1998/ 99 and 2003/04) is shown in Table 2.

\section{Total ambulatory care sensitive conditions}

Between 1998 and 2004, standardised rates of admissions for total ACSCs doubled among the refugee-source country-born, from 18.7 per 1000 persons [95\%CI, 16.1-21.7] in $1998 / 99$ to 35.5 per 1000 persons [95\%CI, 32.5-38.7] in $2003 / 04$. Among the Australia-born population, the rates of total ACSCs admissions also increased from 31.9

Table I: Ambulatory Care Sensitive Conditions (ACSC) and ICD-I 0-AM codes used in the analyses

\begin{tabular}{|c|c|c|}
\hline Category & ICD-IO-AM codes & Notes \\
\hline Influenza and pneumonia & 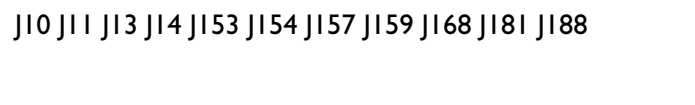 & $\begin{array}{l}\text { In any diagnosis field, excludes cases with } \\
\text { secondary diagnosis of D57, and people under } 2 \\
\text { months }\end{array}$ \\
\hline Other vaccine preventable & $\begin{array}{l}\text { A35 A36 A37 A80 B05 B06 BI6I BI69 BI80 BI8I B26 } \\
\text { G000 M0I4 }\end{array}$ & In any diagnosis field \\
\hline Asthma & $\mathrm{J} 45 \mathrm{~J} 46$ & Principal diagnosis only \\
\hline Congestive heart failure & $1501110 \mathrm{~J} 81$ & Principal diagnosis only \\
\hline Diabetes complications & 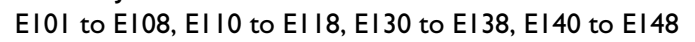 & In any diagnosis field \\
\hline $\begin{array}{l}\text { Chronic obstructive pulmonary } \\
\text { disease }\end{array}$ & $\mathrm{J} 20 \mathrm{~J} 4 \mathrm{I} \mathrm{J} 42 \mathrm{~J} 43 \mathrm{~J} 44 \mathrm{~J} 47$ & $\begin{array}{l}\text { Principal diagnosis only, J20 only with diag2 of J4I } \\
\text { J42 J43 J44 J47 }\end{array}$ \\
\hline Angina & $12012401248 I 249$ & $\begin{array}{l}\text { Principal diagnosis only, excludes cases with } \\
\text { procedures codes NOT in blocks } 1820 \text { to } 2140\end{array}$ \\
\hline Iron deficiency anaemia & D50I D508 D509 & Principal diagnosis only \\
\hline Hypertension & 1101119 & Principal diagnosis only \\
\hline Nutritional deficiencies & $\mathrm{E} 40$ to $\mathrm{E} 43, \mathrm{E} 550 \mathrm{E} 643$ & Principal diagnosis only \\
\hline Dehydration and gastroenteritis & E86 K522 K528 K529 & Principal diagnosis only \\
\hline Pyelonephritis & NI0 NII NI2 NI36 N390 & Principal diagnosis only \\
\hline Perforated/bleeding ulcer & $\begin{array}{l}\text { K } 250 \text { K25I K252 K254 K255 K256 K260 K26I K262 } \\
\text { K264 K265 K266 K270 K27I K272 K274 K275 K276 } \\
\text { K280 K28I K282 K284 K285 K286 }\end{array}$ & Principal diagnosis only \\
\hline Cellulitis & L03 L04 L08 L88 L980 L983 & $\begin{array}{l}\text { Principal diagnosis only, excludes cases with any } \\
\text { procedure except those in blocks I } 820 \text { to } 2016 \text { of } \\
\text { if procedure is } 302 \text { I 6-02 } 30676-0030223-02 \\
30064-0034527-0134527-0090661-00 \text { and this is } \\
\text { the only listed procedure }\end{array}$ \\
\hline Pelvic inflammatory disease & N70 N73 N74 & Principal diagnosis only \\
\hline Ear, nose and throat infections & $\mathrm{H} 66 \mathrm{H} 67 \mathrm{~J} 02 \mathrm{~J} 03 \mathrm{~J} 06 \mathrm{~J} 3 \mathrm{I} 2$ & Principal diagnosis only \\
\hline Dental conditions & $\mathrm{K} 02$ to $\mathrm{K} 06, \mathrm{~K} 08 \mathrm{~K} 098 \mathrm{~K} 099 \mathrm{KI} 2 \mathrm{KI} 3$ & Principal diagnosis only \\
\hline Convulsions and epilepsy & OI5 G40 G4I R56 & Principal diagnosis only \\
\hline Gangrene & $\mathrm{R} 02$ & In any diagnosis field \\
\hline
\end{tabular}


Table 2: Number of hospital admissions (N), standardised ratios (SR) and $95 \%$ confidence levels $(95 \% \mathrm{Cl})$ for total, acute, chronic, and vaccine-preventable ambulatory care sensitive conditions (ACSCs) for persons born in refugee-source countries, 1998/99 to 2003/04

\begin{tabular}{|c|c|c|c|c|c|c|c|c|c|c|c|c|c|}
\hline \multirow[t]{2}{*}{ ACSCs } & \multicolumn{2}{|c|}{ 1998/99 } & \multicolumn{2}{|c|}{$1999 / 2000$} & \multicolumn{2}{|c|}{$2000 / 01$} & \multicolumn{2}{|c|}{$2001 / 02$} & \multicolumn{2}{|c|}{$2002 / 03$} & \multicolumn{2}{|c|}{$2003 / 04$} & \multirow{2}{*}{$\begin{array}{c}\text { Total } \\
\mathbf{N}\end{array}$} \\
\hline & $\mathrm{N}$ & $\begin{array}{c}\mathrm{SR} \\
(95 \% \mathrm{Cl})\end{array}$ & $\mathrm{N}$ & $\begin{array}{c}\text { SR } \\
(95 \% \mathrm{Cl})\end{array}$ & $\mathrm{N}$ & $\begin{array}{c}\text { SR } \\
(95 \% \mathrm{Cl})\end{array}$ & $\mathrm{N}$ & $\begin{array}{c}\text { SR } \\
(95 \% \mathrm{Cl})\end{array}$ & $N$ & $\begin{array}{c}\text { SR } \\
(95 \% \mathrm{Cl})\end{array}$ & $N$ & $\begin{array}{c}\text { SR } \\
(95 \% \mathrm{Cl})\end{array}$ & \\
\hline Total & 254 & $\begin{array}{c}18.7 \\
(16.1,21.7)\end{array}$ & 298 & $\begin{array}{c}21.4 \\
(18.6,24.5)\end{array}$ & 518 & $\begin{array}{c}29.8 \\
(27.0,32.8)\end{array}$ & 572 & $\begin{array}{c}32.4 \\
(29.5,35.6)\end{array}$ & 569 & $\begin{array}{c}31.9 \\
(29.0,35.0)\end{array}$ & 680 & $\begin{array}{c}35.5 \\
(32.5,38.7)\end{array}$ & 2891 \\
\hline Acute & 112 & $\begin{array}{c}6.4 \\
(5.1,8.1)\end{array}$ & 145 & $\begin{array}{c}7.8 \\
(6.4,9.6)\end{array}$ & 199 & $\begin{array}{c}8.1 \\
(6.9,9.5)\end{array}$ & 259 & $\begin{array}{c}11.7 \\
(10.1,13.4)\end{array}$ & 249 & $\begin{array}{c}10.5 \\
(9.0,12.1)\end{array}$ & 322 & $\begin{array}{c}13.0 \\
(11.4,14.8)\end{array}$ & 1286 \\
\hline Chronic & 124 & $\begin{array}{c}11.4 \\
(9.3,14.0)\end{array}$ & 138 & $\begin{array}{c}12.5 \\
(10.3,15.2)\end{array}$ & 307 & $\begin{array}{c}21.2 \\
(18.8,23.9)\end{array}$ & 296 & $\begin{array}{c}20.1 \\
(17.7,22.7)\end{array}$ & 311 & $\begin{array}{c}21.1 \\
(18.7,23.8)\end{array}$ & 343 & $\begin{array}{c}22.2 \\
(19.7,25.0)\end{array}$ & 1519 \\
\hline $\begin{array}{l}\text { Vaccine- } \\
\text { preventable }\end{array}$ & 18 & $\begin{array}{c}0.8 \\
(0.5,1.6)\end{array}$ & 17 & $\begin{array}{c}1.2 \\
(0.7,2.2)\end{array}$ & 15 & $\begin{array}{c}0.7 \\
(0.4,1.4)\end{array}$ & 24 & $\begin{array}{c}1 . I \\
(0.6,1.7)\end{array}$ & 18 & $\begin{array}{c}0.9 \\
(0.5,1.5)\end{array}$ & 25 & $\begin{array}{c}1.0 \\
(0.6,1.6)\end{array}$ & 117 \\
\hline
\end{tabular}

per 1000 persons [95\%CI, 31.3-32.6] in 1998/99 to 43.2 per 1000 persons [95\%CI, 42.4-44.1] in 2003/04. Figure 1 compares total ACSCs admission rate ratios between refugee-source country-born and the Australia-born average.

\section{Acute ambulatory care sensitive conditions}

For the refugee-source country-born, rates of acute ACSC admissions doubled between 1998/99 and 2003/04, increasing from 6.4 per 1000 persons [95\%CI, 5.1-8.1] in $1998 / 99$ to 16.7 per 1000 persons [95\%CI, 11.4-14.8] in 2003/04. Among the Australia-born, admission rates of acute ACSCs also increased from 12.9 per 1000 persons [95\%CI, $12.5-13.3$ ] in $1998 / 99$ to 16.7 per 1000 persons [95\%CI, 16.2-17.3] in 2003/04. A comparison of acute ACSC admission rate ratios between the two population groups is presented in Figure 2.

\section{Chronic ambulatory care sensitive conditions}

The standardised rates of admission for chronic ACSCs doubled among the refugee-source country-born between 1998/99 and 2003/04. Rates increased from 11.4 admis-

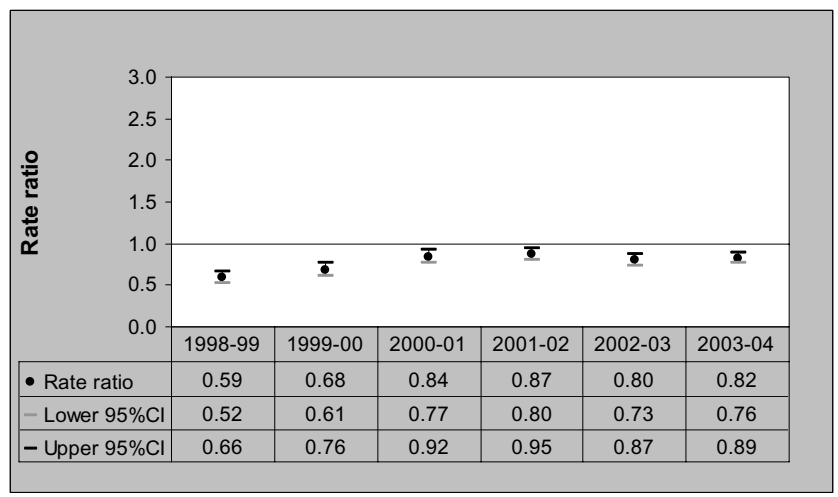

\section{Figure I}

Total ACSCs Admission Rate Ratios - Refugee-source country-born (Australia-born = I), 1998/99 to 2003/04. sions per 1000 persons [95\%CI, 9.3-14.0] in 1998/99 to 22.2 per 1000 persons [95\%CI, 19.7-25.0] in 2003/04. Rates of admissions amongst the Australia-born increased from 17.9 per 1000 persons [95\%CI, 17.4-18.5] in 1998/ 99 to 26.2 per 1000 persons [95\%CI, 25.5-27.0] in 2003/ 04. Figure 3 compares chronic ACSC admission rate ratios between the refugee-source country-born and the Australia-born over the six-year period.

\section{Vaccine-preventable ambulatory care sensitive conditions}

There was no consistent pattern of admission rates for vaccine-preventable ACSCs among the refugee-source country-born population over the six-year period. The lowest admission rate was 0.7 per 1000 persons [95\%CI, 0.41.4 ] in $2000 / 01$ and the highest was 1.2 per 1000 persons [95\%CI, 0.7-2.2] in 1999/2000. Among the Australiaborn, the rates of vaccine-preventable ACSC admissions decreased from 1.4 per 1000 persons [95\%CI, 1.3-1.6] in $1998 / 99$ to 0.8 per 1000 persons [95\%CI, 0.7-1.0] in 2003/04. A comparison of vaccine-preventable ACSC

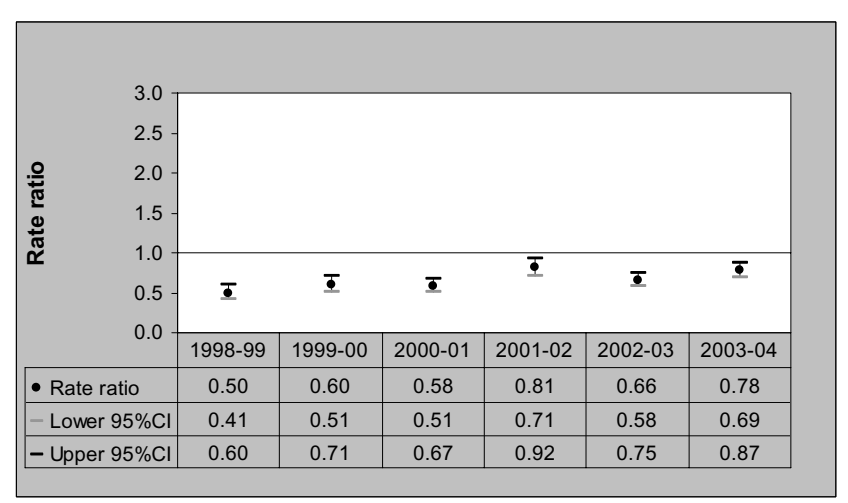

\section{Figure 2}

Acute ACSCs Admission Rate Ratios - Refugee-source country-born (Australia-born = I), 1998/99 to 2003/04. 


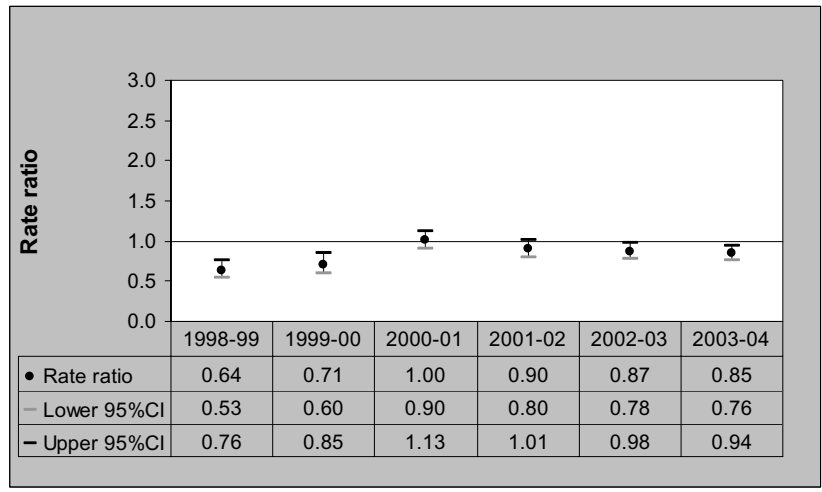

\section{Figure 3}

Chronic ACSCs Admission Rate Ratios - Refugee-source country-born (Australia-born = I), 1998/99 to 2003/04.

admission rate ratios between the two groups is shown in Figure 4 .

\section{Discussion}

To our knowledge, this is the first study that has investigated ACSHs in resettled refugee populations. Contrary to our hypothesis, the study has found lower total and acute rates and similar chronic and vaccine-preventable rates of ACSHs among refugee-source country-born persons when compared to the Australia-born population.

A number of studies have previously examined the effects of race and ethnicity on ACSHs in industrialised countries. Shah et al [24] found that the Aboriginal population in Ontario, Canada, had significantly higher admission rates for ACSCs compared with the general Ontario population. Similarly, Stamp et al [11] reported higher ACSHs among Australian Aboriginal and Torres Strait Islander

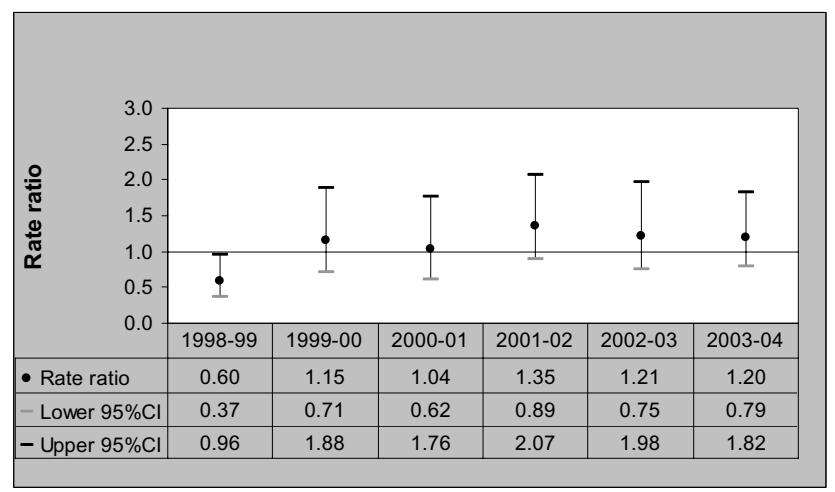

Figure 4

Vaccine-preventable ACSCs Admission Rate Ratios - Refugee-source country-born (Australia-born = I), 1998/99 to 2003/04. populations than non-Aboriginal and Torres Strait Islanders. Other studies have consistently found higher preventable hospitalisation rates among African Americans and Hispanics than non-Hispanic whites in the USA $[3,9,10]$.

The effects of immigration status on ACSHs have been scarcely investigated. Glazier et al [25] examined ACSHs in high recent-immigration areas in Toronto, Canada, and found that the areas with the highest quintile of recent immigration reported the highest relative rates of ACSHs. In contrast, a study by DeLia [26] used births to immigrant mothers as a proxy for immigrant population in the USA and found this variable to be associated with lower ACSHs. These studies however did not discriminate across immigrant categories.

Given the lack of international literature on ACSHs among refugee communities it is not possible to determine whether the findings of our study are unique to Australia or may apply to other resettlement countries. Although refugees may share some of the characteristics of other immigrants, they have experienced extraordinary circumstances of stress and trauma prior to entering the country of resettlement, and therefore are likely to have poorer health status, particular vulnerability to specific health conditions, and higher need to health care [14,27]. In this context, we had hypothesised that refugee populations would have higher rates of hospital admissions, including ACSHs, than the native-born. On the contrary, we have previously found either similar or lower rates of hospital utilisation among residents born in refugeesource countries compared with the Australia-born population [28]. Our findings demonstrate also either similar or lower rates of ACSHs among the refugee-source country-born population.

Following Ansari et al categorisation [2], there are at least three groups of factors that may provide an explanation for these findings: health factors, social determinants, and behavioural risk factors. The health factors group include disease prevalence, propensity to seek care, and physician supply. Our results may indicate that recent refugee arrivals have lower morbidity, as measured by ACSHs, thus confirming the 'healthy migrant effect'[14]. The health requirement that refugees undergo before entering Australia may be selecting those who are healthier [29]There may be also a time lag in the built up of relevant risk factors for some ACSCs such as asthma, diabetes, hypertension and ischaemic heart disease [13] as new arrivals are exposed to the same environment and adopt some of the unhealthy habits (i.e. smoking, drinking, eating junk food) of the receiving society [14]. The overall increase of ACSHs among the refugee-source country-born towards Australia-born averages over the six-year time period may support this argument. The findings may also suggest that 
refugees seek care earlier in the course of chronic disease and therefore are less likely to require hospitalisation. It might be also that Australia's universal health care cover and the adequate levels of physician supply available in urban areas, where most refugees settle, lead to 'timely and effective outpatient care' hence reducing the risks of preventable hospitalisations. Nevertheless, there is recent evidence of important health issues in primary care settings (i.e. inadequate vaccinations, nutritional deficiencies, infectious/parasitic diseases, dental disease, musculoskeletal problems) among newly arrived refugees in Australia and of the need for comprehensive health assessments for this population [30,31]. While State governments in Australia are implementing a number of strategies to address the health care needs of recently arrived refugee communities [32], there is emerging evidence of the multiple barriers that affect access to primary and acute health care among this population [30,33,34]. Among these barriers are language barriers, financial disadvantage, lack of information about health issues, poor understanding of how to access health care facilities, and structural barriers within these services [33]. Free or subsidised medical care, like the one provided in a number of refugee resettlement countries, "does not imply equal access to services nor equity in service" [35] (p.165).

In the social determinants group, appropriate levels of income, employment, and education may benefit health care-seeking behaviour or patient education, which may lead to low ACSHs $[4,36]$. However, although people from refugee backgrounds are not a homogeneous population, there is evidence of economic hardship, high levels of unemployment [37], and low levels of educational attainment $[17,38]$ among recent refugee arrivals to Australia. When considering the behavioural risk factors group, our findings may suggest good health habits (i.e. low levels of smoking and alcohol consumption, adequate nutrition and physical activity) among people born in refugee-source countries, which may lead to a decreased risk of ACSHs. Although there is emerging evidence of nutritional deficiencies among recent refugee arrivals [30], mostly due to poor nutrition while living in refugee camps prior to resettling in Australia, and some indication of refugees being at an increased risk for substance misuse [39], very little is known about health habits among recent refugee arrivals to developed countries.

Our study has several limitations. First, the lack of baseline information on immigration status for people attending acute health care settings prompted the use of country of birth as a proxy for refugee status. Our estimates indicate that approximately $80 \%$ of arrivals between 1996 and 2004 born in the eight refugee-source countries entered Australia under the humanitarian resettlement program [28]. Second, as data reporting disease prevalence by country of birth was not readily available for the selected refugee-source countries, we were unable to adjust for this variable. This is important as "differing disease prevalence might account for differences in preventable hospitalization" [9] (p.249). However, previous research has found that, independent of prevalence, better access to health care in Victoria was associated with lower ACSH rates [2]. Third, we were unable to adjust for length of time in Australia as it was not available in the hospital dataset. It can be argued that recent refugee arrivals would be less likely to seek health care during the initial period of resettlement as they are focused in addressing 'more pressing' issues such as housing, employment, children education, and family reunion. Those who have been in the country for a shorter period of time may also have less knowledge about how to navigate through the health care system. Fourth, the analyses could not be extended to smaller areas such as the local governments and primary care partnerships due to small numbers. Small area analyses on refugee populations along with ad-hoc surveys will be useful in identifying access barriers refugees face in health care settings. These access barriers can be economic, structural, geographic, or cultural. Unpacking these dimensions of access will have the potential to provide the basis for policy makers to develop targeted public health and health services interventions.

\section{Conclusion}

This study represents a significant step towards the development of an evidence-based knowledge around resettled refugee populations and preventable hospitalisation. Despite emerging evidence of important health issues among recently arrived refugee populations, we have found that preventable hospitalisation rates among people born in refugee-source countries are either similar or lower than Australia-born averages. Our study has been unable to elucidate whether low rates of preventable hospitalisation among this refugee population indicate better health status, appropriate health habits, timely and effective care-seeking behaviour and outpatient care, or overall low levels of health care-seeking due to other more pressing needs during the initial period of resettlement. More research is needed to clarify these issues. It is important to unpack dimensions of health status and health care access in refugee populations through ad-hoc surveys as the refugee population is not a homogenous group despite sharing a common experience of forced displacement and violence-related trauma. Factors such as ethnicity, gender, culture, socio-economic and educational status, health systems and services in the country of origin, and the particular contexts of displacement, flight, and resettlement play an important role in a refugee's experience of ill health and, consequently, of health care utilisation and health-related outcomes in countries of resettlement. 


\author{
Abbreviations \\ ACSCs - Ambulatory Care Sensitive Conditions \\ ACSH - Hospitalisation for Ambulatory Care Sensitive \\ Conditions
}

ICD-10-AM - International Statistical Classification of Diseases and Related Health Problems, 10th Revision, Australian Modification

VAED - Victorian Admitted Episodes Dataset

\section{Competing interests}

The author(s) declare that they have no competing interests.

\section{Authors' contributions}

IC-V participated in the design of the study, conducted the statistical analysis, and drafted the manuscript.

ZA provided advice on the conceptualisation and measurement of ACSCs, design of the study and data analysis, and reviewed the manuscript.

VS participated in the study design, provided advice on data analysis, and reviewed the manuscript.

$\mathrm{KB}$ participated in the design of the study and reviewed the manuscript.

SMG participated in the design of the study and reviewed the manuscript.

\section{Acknowledgements}

The authors gratefully acknowledge funding support from the Refugee Health Research Centre, La Trobe University, and in-kind support from the Chronic Disease Surveillance and Epidemiology Section, Victorian Department of Human Services. We also acknowledge the useful comments of the reviewers.

The VAED data was supplied by the Victorian Department of Human Services. The paper presents the findings and conclusions of the authors; it does not necessarily represent the views of the Victorian Department of Human Services.

Ignacio Correa-Velez is supported by a National Health and Medical Research Council (NHMRC) Public Health (Australia) Fellowship (Grant No. 380845).

\section{References}

I. Billings ], Anderson GM, Newman LS: Recent findings on preventable hospitalizations. Health Aff (Millwood) 1996, I 5(3):239-249.

2. Ansari Z, Laditka JN, Laditka SB: Access to health care and hospitalization for ambulatory care sensitive conditions. Med Care Res Rev 2006, 63:7| 9-74I.

3. Laditka JN, Laditka SB, Mastanduno MP: Hospital utilization for ambulatory care sensitive conditions: health outcome disparities associated with race and ethnicity. Soc Sci Med 2003, 57:|429-|44|.
4. Billings J, Zeitel L, Lukomnic J, Carey TS, Blank AE, Newman L: Impact of socioeconomic status on hospital use in New York City. Health Aff (Millwood) 1993, I2(1):162-173.

5. Blustein J, Hanson K, Shea S: Preventable hospitalizations and socioeconomic status. Health Aff (Millwood) 1998, I7(2): 177-189.

6. Weissman JS, Gatsonis C, Epstein AM: Rates of avoidable hospitalization by insurance status in Massachusetts and Maryland. JAMA 1992, 268:2388-2394.

7. Falik M, Needleman J, Wells BL, Korb J: Ambulatory care sensitive hospitalizations and emergency visits: experiences of Medicaid patients using federally qualified health centers. Med Care 200I, 39:55I-56I.

8. Gill JM, Mainous III AG: The role of provider continuity in preventing hospitalizations. Arch Fam Med 1998, 7:352-357.

9. Laditka JN, Laditka SB: Race, ethnicity and hospitalization for six chronic ambulatory care sensitive conditions in the USA. Ethn Health 2006, I I:247-263.

10. Gaskin DJ, Hoffman C: Racial and ethnic differences in preventable hospitalizations across 10 states. Med Care Res Rev 2000, 57(SuppI I):85-107.

II. Stamp KM, Duckett SJ, Fisher DA: Hospital use for potentially preventable conditions in Aboriginal and Torres Strait Islander and other Australian populations. Aust N Z J Public Health 1998, 22:673-678.

12. UNHCR: The State of the World's Refugees: Human Displacement in the New Millenium. New York, Oxford University Press Inc; 2006.

13. Thomas SL, Thomas SDM: Displacement and Health. Br Med Bull 2004, 69: II 15-127.

14. Beiser $M$ : The health of immigrants and refugees in Canada. Can J Public Health 2005, 96(Suppl 2):S30-S44.

15. Acute Health Division: The Victorian Admitted Episodes Dataset: an overview. Melbourne, Victoria , Department of Human Services; 200 I.

16. University of Sydney: ICD-10-AM. Australian Coding Standards, Volume 5 of the International Statistical Classification of Diseases and Related Health Problems, I0th Revision, Australian Modification (ICD-10-AM). 2nd edition. Sydney, Centre for Classification of Health, Faculty of Health Sciences; 2000.

17. Department of Immigration and Multicultural Affairs: Settlement Database. Canberra , DIMA; 2005.

18. Jupp J: The Australian People. An Encyclopedia of the Nation, Its People and Their Origins. Oakleigh, Victoria , Cambridge University Press; 200I.

19. Ansari MZ, Henderson T: The Victorian Ambulatory Care Sensitive Conditions Study: Opportunities for Targeting Public Health and Health Services Interventions. Melbourne, Victoria Department of Human Services; 2002.

20. Millman M: Access to Health Care in America: Report of a study by the Committee on Monitoring Access to Personal Health Care Services, Institute of Medicine. Washington , National Academy Press; 1993.

21. Kirkwood BR, Sterne JAC: Essential Medical Statistics. 2nd edition. Malden, Massachusetts, Blackwell Science; 2003.

22. Australian Bureau of Statistics: Census of Population and Housing, 1996 and $200 \mathrm{I}$. Number of persons by sex, by age, by birthplace of individual, by area of usual residence (Victoria and Australia). Canberra, ABS; 2005.

23. Fay MP, Feuer EJ: Confidence intervals for directly standardized rates: A method based on the gamma distribution. Stat Med 1997, 16:791 -780I.

24. Shah BR, Gunraj N, Hux JE: Markers of access to and quality of primary care for aboriginal people in Ontario, Canada. Am J Public Health 2003, 93:798-802.

25. Glazier RH, Creatore MI, Cortinois AA, Agha MM, Moineddin R: Neighbourhood recent immigration and hospitalization in Toronto, Canada. Can J Public Health 2004, 95:130-134.

26. DeLia $D$ : Distributional issues in the analysis of preventable hospitalizations. Health Serv Res 2003, 38:176I-1779.

27. Iversen VC, Morken G: Acute admissions among immigrants and asylum seekers to a psychiatric hospital in Norway. Soc Psychiatry Psychiatr Epidemiol 2003, 38(9):5 I 5-519.

28. Correa-Velez I, Sundararajan V, Brown K, Gifford SM: Hospital utilisation among people born in refugee-source countries: An analysis of hospital admissions, Victoria, 1998-2004. MJA 2007, I 86(II):577-580. 
29. Department of Immigration and Citizenship: Fact Sheet 22: The Health Requirement. Canberra , Commonwealth of Australia; 2007.

30. Tiong ACD, Patel MS, Gardiner J, Ryan R, Linton KSW K A, Scopel J, Biggs BA: Health Issues in newly arrived African refugees attending general practice clinics in Melbourne. MJA 2006, I 85:602-606.

31. Martin JA, Mak DB: Changing faces: a review of infectious disease screening of refugees by the Migrant Health Unit, Western Australia in 2003 and 2004. MJA 2006, 185:607-6I0.

32. Victorian Department of Human Services: Refugee health and wellbeing action plan. Melbourne, Policy Projects Branch, Victorian Government Department of Human Services; 2005.

33. Sheikh-Mohammed M, Maclntyre CR, Wood NJ, Leask J, Isaacs D: Barriers to access to health care for newly resettled subSaharan refugees in Australia. MJA 2006, I 85:594-597.

34. Davidson N, Skull S, Burgner D, Kelly P, Raman S, Silove D, Steel Z, Vora $R$, Smith $M$ : An issue of access: Delivering equitable health care for newly arrived refugee children in Australia. J Paediatr Child Health 2004, 40:569-575.

35. Kliewer EV, Butler JRG: Hospital morbidity patterns and costs of immigrants in Australia. Canberra , National Centre for Epidemiology and Population Health, Australian National University; 1995.

36. Laditka SB, Laditka JN: Geographic variation in preventable hospitalization of older women and men: implications for access to primary health care. J Women Aging 1999, I I(4):43-56.

37. Colic-Peisker V, Tilbury F: Employment niches for recent refugees: Segmented labour market in twenty-first century Australia. Journal of Refugee Studies 2006, I9(2):203-229.

38. Allender SC: Australia's Migrants and Refugees: Opening the Door to Lifelong Learning. How Adults Learn a New Language. In International Conference on "How Adults Learn" Washington, DC; 1998.

39. Sowey $\mathrm{H}$ : Are refugees at increased risk of substance misuse? Sydney, Drug and Alcohol Multicultural Education Centre; 2005.
Publish with Bio Med Central and every scientist can read your work free of charge

"BioMed Central will be the most significant development for disseminating the results of biomedical research in our lifetime. "

Sir Paul Nurse, Cancer Research UK

Your research papers will be:

- available free of charge to the entire biomedical community

- peer reviewed and published immediately upon acceptance

- cited in PubMed and archived on PubMed Central

- yours - you keep the copyright
BioMedcentral 